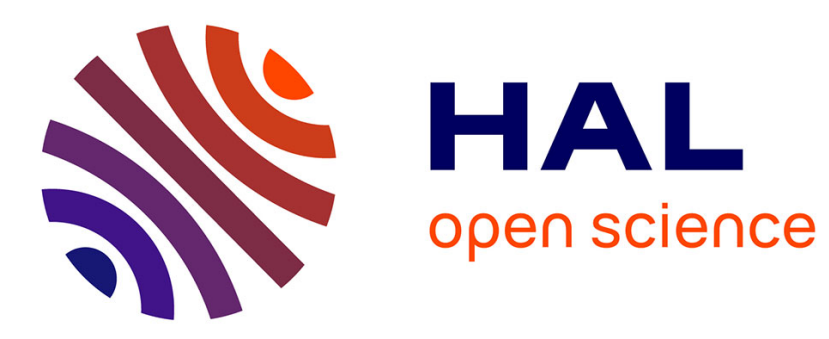

\title{
A Cryogen-Consumption-Free System for Dynamic Nuclear Polarization at 9.4 T
}

Mathieu Baudin, Basile Vuichoud, Aurélien Bornet, Geoffrey Bodenhausen, Sami Jannin

\section{- To cite this version:}

Mathieu Baudin, Basile Vuichoud, Aurélien Bornet, Geoffrey Bodenhausen, Sami Jannin. A CryogenConsumption-Free System for Dynamic Nuclear Polarization at 9.4 T. Journal of Magnetic Resonance, 2018, 294, pp.115-121. 10.1016/j.jmr.2018.07.001 . hal-01832957

\section{HAL Id: hal-01832957 https://hal.science/hal-01832957}

Submitted on 13 Jul 2018

HAL is a multi-disciplinary open access archive for the deposit and dissemination of scientific research documents, whether they are published or not. The documents may come from teaching and research institutions in France or abroad, or from public or private research centers.
L'archive ouverte pluridisciplinaire HAL, est destinée au dépôt et à la diffusion de documents scientifiques de niveau recherche, publiés ou non, émanant des établissements d'enseignement et de recherche français ou étrangers, des laboratoires publics ou privés. 


\title{
A Cryogen-Consumption-Free System for Dynamic Nuclear Polarization at $9.4 \mathrm{~T}$
}

\author{
Mathieu Baudin $^{a}{ }^{*}$, Basile Vuichoud ${ }^{c}$, Aurélien Bornet ${ }^{b}$, Geoffrey Bodenhausen $^{a}$ and Sami Jannin ${ }^{c}$ \\ a Laboratoire des biomolécules, LBM, Département de chimie, École normale supérieure, PSL University, Sorbonne Université, CNRS, 75005 Paris, \\ France \\ b Institut des sciences et ingénierie chimiques (ISIC), Ecole PolytechniqueFédérale de Lausanne (EPFL), 1015 Lausanne, Switzerland \\ c Université de Lyon, CNRS, Université Claude Bernard Lyon 1, ENS de Lyon, Institut des Sciences Analytiques, UMR 5280, 69100 Villeurbanne, France
}

1.

\section{ARTICLE INFO}

Article history:

Received 00 December 00

Received in revised form 00 January 00

Accepted 00 February 00

\section{Keywords:}

Dynamic nuclear polarization (DNP)

Dissolution DNP

Cryogen-consumption-free magnets

Adiabatic cross polarization

\begin{abstract}
A B S T R A C T
A novel system for dissolution dynamic nuclear polarization based on a cost-effective "cryogen-free" magnet that can generate fields up to $9.4 \mathrm{~T}$ with a sample space that can reach temperatures below $1.4 \mathrm{~K}$ in a continuous and stable manner. Polarization levels up to $P\left({ }^{1} \mathrm{H}\right)=60 \pm 5 \%$ can be reached with TEMPOL in about $20 \mathrm{~min}$, and $P\left({ }^{13} \mathrm{C}\right)=50 \pm 5 \%$ can be achieved using adiabatic cross polarization.
\end{abstract}

Dissolution dynamic nuclear polarization (D-DNP) has become increasingly popular in nuclear magnetic resonance spectroscopy (NMR) and imaging (MRI) because it can enhance the signals by several orders of magnitude [1]. D-DNP experiments consist of polarizing nuclear spins in samples doped with radicals or other paramagnetic polarizing agents (PAs), placed in a strong magnetic field (typically $3.35<B_{0}<6.7 \mathrm{~T}$ in most laboratories) at typical temperatures $1.2<T<4.2 \mathrm{~K}$. The electron spin polarization $P_{\mathrm{e}}$ is saturated $\left(P_{\mathrm{e}} \approx 0\right)$ by microwave irradiation and the DNP effect causes a build-up of the polarization $P(I)$ of protons and other nuclei $I={ }^{2} \mathrm{H},{ }^{6} \mathrm{Li},{ }^{13} \mathrm{C},{ }^{15} \mathrm{~N},{ }^{31} \mathrm{P}$, etc. The sample is then rapidly dissolved and the nuclear signals are detected in liquid phase in an NMR spectrometer or MRI scanner. The higher the ratio $B_{0} / T$, the higher the electron polarization $P_{\mathrm{e}}$, and, concomitantly, the electron spin relaxation times $T_{1 \mathrm{e}}$ often become longer so that a weak microwave irradiation is sufficient to achieve saturation [2]. The line-widths of the proton NMR spectra are determined by dipole-dipole couplings and often exceed $40 \mathrm{kHz}$ regardless of $B_{0}$ so that there is no need for expensive highresolution NMR magnets that can offer a homogeneity $\Delta B_{0} / B_{0}<1 \mathrm{ppb}$ (e.g. proton linewidths of $0.4 \mathrm{~Hz}$ out of $400 \mathrm{MHz}$ at $9.4 \mathrm{~T}$ ) but are not suitable to ramp the $B_{0}$ field to arbitrary values. For DNP applications, socalled "cryogen-free" or "dry" superconducting magnets that are equipped with built-in helium liquefier and therefore do not require any liquid helium or nitrogen appear more attractive. Such magnets can be ramped to various fields $B_{0}$ and their modest homogeneity $\Delta B_{0} / B_{0}<10 \mathrm{ppm}$ suffices for DNP. The samples can be cooled using a helium bath cryostat [3], [4] that typically consumes more than 10 liters of liquid helium per day of operation, which translates into significant running costs, and the need to refill liquid helium makes it difficult to run extensive series of experiments continuously over several days. Alternatively, a variable temperature insert (VTI) can be used, like in the "Hypersense" marketed by Oxford Instruments, which operates at $B_{0}=3.35 \mathrm{~T}$ and $T<1.2 \mathrm{~K}$. The "SpinLab" polarizer designed by General Electric [5] is equipped with a cryo-cooler and a sorption pump and operates in "cryogen-free" mode at $B_{0}=5 \mathrm{~T}$ and $T<1.2 \mathrm{~K}$. This sophisticated system (ca $2 \mathrm{M} €$ ) has been designed for sterile clinical use, which is not required for most preclinical MRI and spectroscopic applications. The apparatus described by Yoshihara, Can, Karlsson, Lerche, Schwitter, and Comment operates at $B_{0}=7 \mathrm{~T}$ [6]. The system designed by Kiswandhi, Niedbalski, Parish, Wang, and Lumata [7] utilizes a variable-field "cryogen-free" superconducting magnet that can be ramped up to $B_{0}=9 \mathrm{~T}$ but was only used at $B_{0}=6.7 \mathrm{~T}$ and is equipped with cryo-coolers that can cool the sample space and DNP assembly down to $T=1.8 \mathrm{~K}$ via the JouleThomson effect. The DNP system described in a lecture by Bowen, Rybalko, Petersen and Ardenkjaer-Larsen is also based on a dry magnet and can in principle be used at $B_{0}=3.35,6.70$, and $10.05 \mathrm{~T}$ [8].

In this Communication, we describe a DNP polarizer based on a dry magnet that can operate up to $B_{0}=9.4 \mathrm{~T}$, as first presented at ENC 2017 [9]. This value was chosen in order to explore the efficiency of DNP at higher fields than $7 \mathrm{~T}$, where we hope to benefit from a higher thermal electronic polarization at higher temperatures $(90.6 \%$ at $4.2 \mathrm{~K}$ and $9.4 \mathrm{~T}$ versus about $80 \%$ at $6.7 \mathrm{~T}$ ). However, we are aware that some DNP mechanisms tend to lose efficiency at higher fields, which could go against the benefits obtained from electronic polarization, and this is why it can easily be energized at lower magnetic fields such as 3.35 and $6.7 \mathrm{~T}$. A VTI that houses both the NMR probe and sample can provide stable temperatures down to $T=1.4 \mathrm{~K}$ in a continuous manner over several days. NMR signals can be excited and observed in alternation on two channels, and cross polarization $(\mathrm{CP})$ can be performed to transfer polarization from ${ }^{1} \mathrm{H}$ to ${ }^{2} \mathrm{H},{ }^{6} \mathrm{Li},{ }^{13} \mathrm{C},{ }^{15} \mathrm{~N},{ }^{31} \mathrm{P}$, etc. [10]-[13]. Both the magnet and the VTI are cooled by means of a helium recycling loop, thus eliminating the need to fill liquid helium, and limiting running costs other than electric power. We present preliminary results obtained with this setup using the inexpensive polarizing agent TEMPOL at $9.4 \mathrm{~T}$ and $1.5 \mathrm{~K}$, yielding a 
proton polarization of $P\left({ }^{1} \mathrm{H}\right)=60 \%$, with a remarkably short build-up time constant $\tau_{\mathrm{DNP}}=120 \mathrm{~s}$, and a carbon-13 polarization of $P\left({ }^{13} \mathrm{C}\right)=50 \%$ in less than one hour (53 $\mathrm{min}$ ) using 9 adiabatic cross-polarization contacts at intervals of $320 \mathrm{~s}$. A new dissolution system derived from the flow-cell design [14] is currently being developed and will be presented elsewhere.

\section{Design of polarizer}

Magnet and integrated VTI with helium recycling circuit

The dry magnet (Figure 1) (Cryogenic Ltd., reference J3997) can be ramped up to $B_{0}=9.4 \mathrm{~T}$. All experiments described in this paper were performed at this field. The magnet is cooled down by an integrated cryocooler (Sumitomo RDK-415D cold head and F-50H compressor) within approximately 30 hours starting from room temperature.

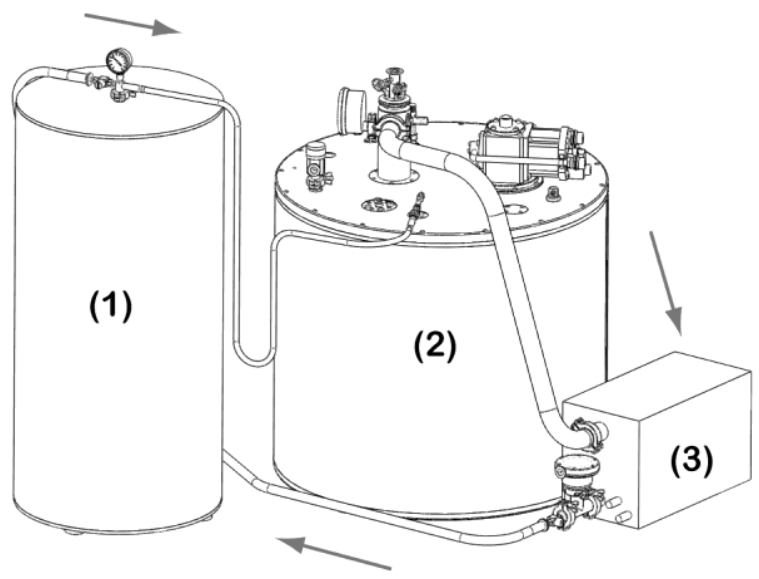

Figure 1: "Cryogen-free" DNP system composed of (1) a helium storage tank $(50 \mathrm{~cm}$ diameter, $100 \mathrm{~cm}$ height $)$, (2) a magnet-VTI system $(80 \mathrm{~cm}$ diameter, and $93 \mathrm{~cm}$ height) with its DNP probe, and (3) a dry pump. Arrows illustrate the helium circuits involved to cool down the magnet, the VTI and the probe.

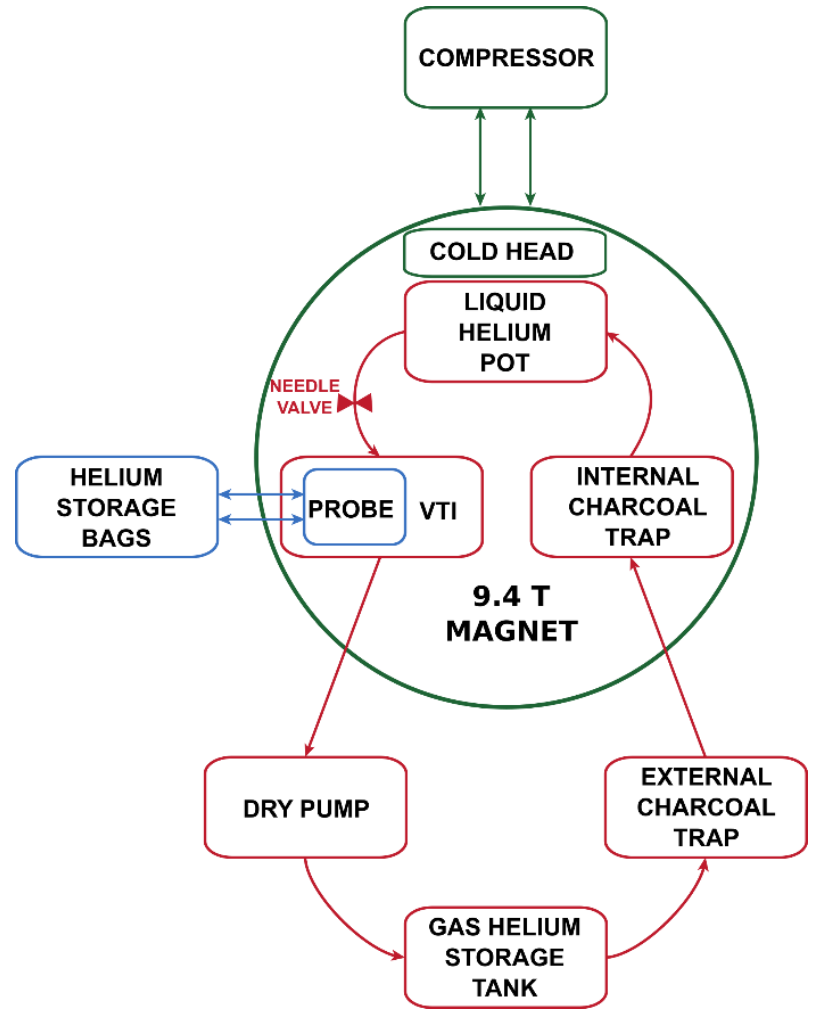

Figure 2: Schematic of the three helium gas circuits used in the apparatus. (Green) Helium gas is used in a closed circuit between the cold head and the compressor to cool the magnet below $3 \mathrm{~K}$. (Red) The VTI cooling-down circuit starts at the gas storage tank. The helium is liquefied in the helium pot after going through two traps to purify it. It enters into the VTI circuit through a needle valve and is recycled towards the storage tank using the dry pump. (Blue) A circuit connects the probe with two 27-L storage bags for helium gas that is cryo-pumped to cool the sample to $4.2 \mathrm{~K}$ or below.

Once it has reached its base temperature $(T \approx 2.5 \mathrm{~K})$, and its magnetic field has been ramped up in approximately 1 hour, a $200 \mathrm{~L}$ storage tank containing helium gas at 20 to $30 \mathrm{kPa}$ over atmospheric pressure is connected to the input port of the cryostat. Helium is then cryo-pumped through two active charcoal traps (one external, immersed in liquid nitrogen at $77 \mathrm{~K}$, and one internal operating below $100 \mathrm{~K}$ ) that prevent impurities from entering into the helium pot where helium is liquefied and stored at $4.2 \mathrm{~K}$. In a few minutes, sufficient liquid helium is collected to fill the $0.5 \mathrm{~L}$ helium pot. It is then fed through a manually operated needle valve into the $43.5 \mathrm{~mm}$ diameter clear access VTI containing the DNP probe (Figure 3 ). The VTI is simultaneously pumped $\left(110 \mathrm{~m}^{3} / \mathrm{h}\right)$ by a dry pump (Edwards iXL120) providing an estimated cooling power of about $0.32{\mathrm{~J} . \mathrm{s}^{-1}}^{-1}$ at $1.4 \mathrm{~K}$. The evaporated helium gas is sent back to the gas storage tank to be re-liquefied in the helium pot in a continuous cycle. This cycle is illustrated in Figure 2. A base sample temperature $T=$ $1.49 \mathrm{~K}$ can be reached after a delay between 100 and 180 minutes (depending on the initial temperature, the needle valve setting, the temperature of the internal charcoal trap, etc.), with a stability of $\pm 0.003 \mathrm{~K}$ for the VTI and $\pm 0.007 \mathrm{~K}$ for the probe over several days of operation (see Figure 5). 


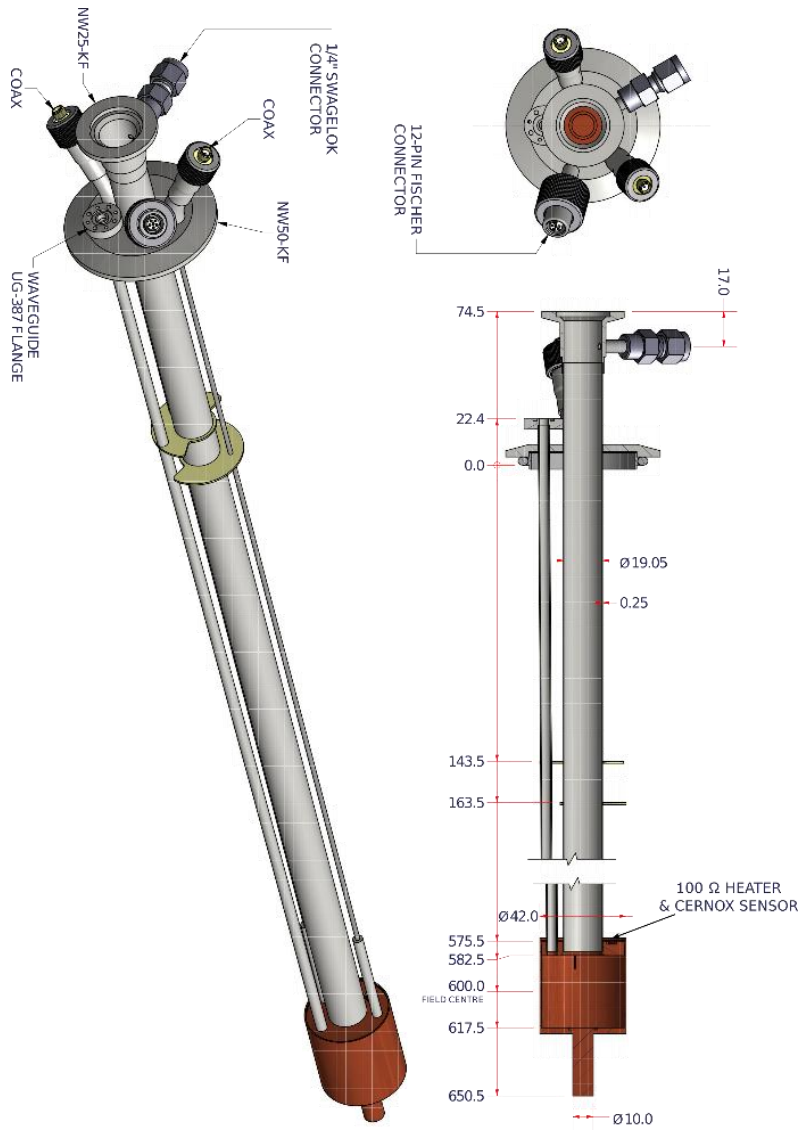

Figure 3: DNP probe with a height of $725 \mathrm{~mm}$ with ISO-KF 50 junction to the VTI flange at the top, and a copper sample space cavity with $42 \mathrm{~mm}$ outer diameter. The probe body is made of stainless steel and has a 24-mm diameter. Reproduced with permission of Cryogenic Ltd.

b) Sample changer

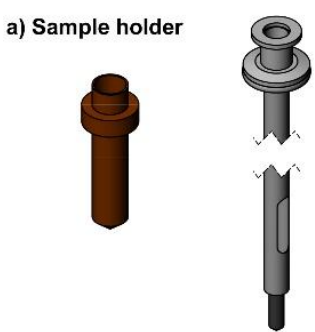

Figure 4: (a) The sample cup (made of PEEK or Teflon) has an 8-mm outer diameter (14 $\mathrm{mm}$ for the upper part), and $45 \mathrm{~mm}$ total height. (b) The sample insert is made of stainless steel (15 mm diameter, $690 \mathrm{~mm}$ height.) The junction with the body of the probe is made with an ISO-KF 25 collar.

\section{DNP probe and sample cup}

The DNP probe (Figure 3) is equipped for microwave irradiation with a $4.5 \mathrm{~mm}$ inner diameter waveguide and a home-built mitre bend. Two radio-frequency (rf) saddle coils can be tuned for ${ }^{1} \mathrm{H}$ and ${ }^{13} \mathrm{C}$ and adapted to other nuclei. The probe has an 18-mm diameter clear access that can accommodate a home-built sample stick and sample holder with $\sim 650 \mu \mathrm{L}$ active volume (Figure 4). It has an additional port to allow the user either to evacuate the probe with a turbo pump, or to connect it to two $27 \mathrm{~L}$ prefilled helium gas bags (Plastigas ${ }^{\circledR}$, Linde). The probe is designed to be leak-tight for superfluid helium, so that the user can precisely control the amount of helium gas that is allowed into the inner volume that contains the sample. The copper sample space cavity is sealed from the VTI using bonding assembly silicone (CAF 1 from Bluestar Silicones France SAS). It has been successfully tested with an overpressure of 1 bar in liquid nitrogen prior to its use under DNP conditions. During operation, $54 \mathrm{~L}$ of helium gas is liquefied in the probe, leading to about $71 \mathrm{~mL}$ of superfluid helium in the sample space. Prior to sample exchange or dissolution, the liquid helium can be evaporated and transferred back into the helium gas bags simply by warming up the probe above $4.2 \mathrm{~K}$ with a built-in heater with a $100 \Omega$ resistance. The temperature at the top of the probe is monitored by a Lake Shore CERNOX sensor (model: CX-1030-SD-HT$1.4 \mathrm{~L}$ ). A second ruthenium oxide resistance (Lake Shore RX-102A) is placed inside of the copper cavity next to the sample to monitor its temperature. The base temperature of the probe and sample $T<1.5 \mathrm{~K}$ remains stable over several days (Figure 5). Inserting a new sample typically takes at most 40 minutes if one evaporates and re-liquefies all of the $c a .70 \mathrm{~mL}$ of liquid helium in the probe (see Figure 6). The build-up of the proton polarization $P^{e q}\left({ }^{1} \mathrm{H}\right)$ in thermal equilibrium at $4.2 \mathrm{~K}$ (i.e, in the absence of microwave irradiation) can be monitored while the helium is being condensed. In practice, most of the helium remains liquid and one can cool down immediately below $1.5 \mathrm{~K}$ in about $10 \mathrm{~min}$ by closing the probe's helium supply, if needed after a quick refill.

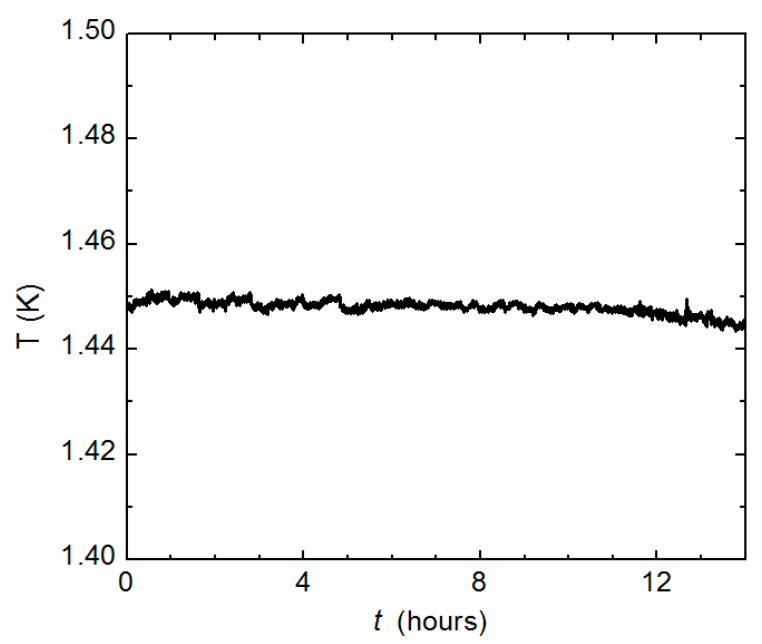

Figure 5: Temperature of the probe monitored over 14 hours, while $75 \mathrm{~mW}$ microwave power is applied continuously. The temperature fluctuations are below $10 \mathrm{mK}$. 


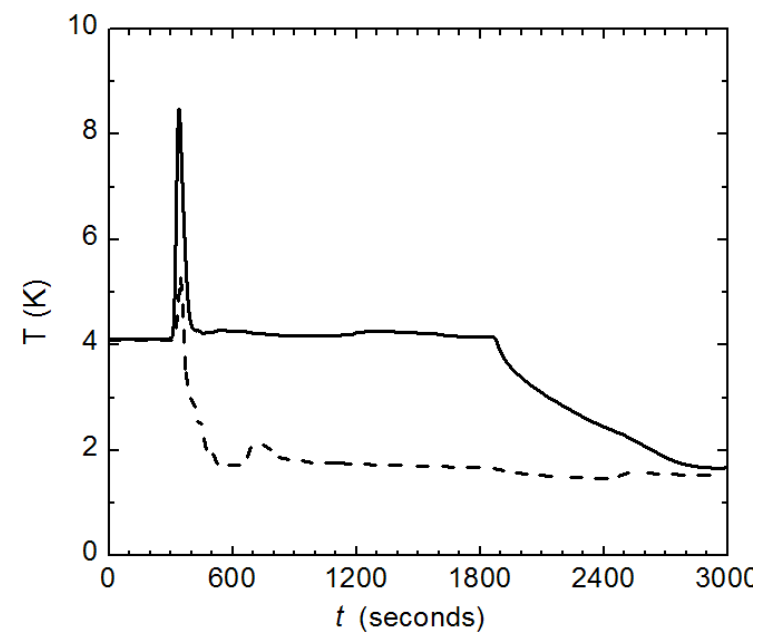

Figure 6: Temperatures of the VTI (dashed line) and probe (solid line) monitored for $50 \mathrm{~min}$ at intervals of $16 \mathrm{~s}$ during sample exchange. Starting at $4.2 \mathrm{~K}$, the VTI temperature reaches approximately $6 \mathrm{~K}$ and the probe $9.5 \mathrm{~K}$ when a new sample is inserted. The probe returns to $4.2 \mathrm{~K}$ in less than $1 \mathrm{~min}$.

\section{Microwave source}

The microwave source provides $c a .75 \mathrm{~mW}$ at $263 \pm 1 \mathrm{GHz}$, generated from a fundamental frequency of about $10.96 \mathrm{GHz}$ (Virginia Diodes synthesizer VDIS-0068) by 4 multiplication steps $(\times 3 \times 2 \times 2 \times 2$, VDI AMC-559). The synthesizer can be programmed to modulate the microwave frequency in a saw-tooth pattern to enhance the efficiency of DNP by saturating a wide range of the EPR spectrum [15]. Typical modulation ranges extend over $100<\Delta f_{\mu w}<200 \mathrm{MHz}$, swept every $100 \mu \mathrm{s}\left(f_{\text {mod }}=10 \mathrm{kHz}\right)$. An attenuation port on the source enables microwave gating controlled by a $0-5 \mathrm{~V}$ signal generated by a Bruker Avance II NMR spectrometer to boost the performance of CP [16].

\section{NMR circuit and spectrometer}

The NMR circuit (Figure 7) features two rf saddle coils with capacitors that are pre-tuned before the probe is cooled down for ${ }^{1} \mathrm{H}$ and ${ }^{13} \mathrm{C}$ at 400 and $100 \mathrm{MHz}$.Tuning and matching is refined after cool-down using external tuning and matching boxes containing two variable capacitors with a range of 8 to $30 \mathrm{pF}$. These boxes are linked via coaxial cables to two solenoid coils, one for each channel, which are then inductively coupled to the saddle coils of the resonator. This design can be adapted to work with other low- $\gamma$ nuclei such as ${ }^{2} \mathrm{H},{ }^{6} \mathrm{Li},{ }^{15} \mathrm{~N},{ }^{31} \mathrm{P}$, etc. This allows one to polarize low- $\gamma$ nuclei by adiabatic $\mathrm{CP}$, which is much faster than direct DNP [10]-[13]. For ${ }^{1} \mathrm{H}$, a $10 \mu \mathrm{s} 90^{\circ}$ pulse $\left(\gamma \mathrm{B}_{1} /(2 \pi)=25 \mathrm{kHz}\right)$ was obtained with $60 \mathrm{~W}$ output power of the $400 \mathrm{MHz}$ amplifier, and for ${ }^{13} \mathrm{C}$, a $12 \mu \mathrm{s} 90^{\circ}$ pulse $\left(\gamma \mathrm{B}_{1} /(2 \pi)=20 \mathrm{kHz}\right)$ with $150 \mathrm{~W}$ at $100 \mathrm{MHz}$. a)

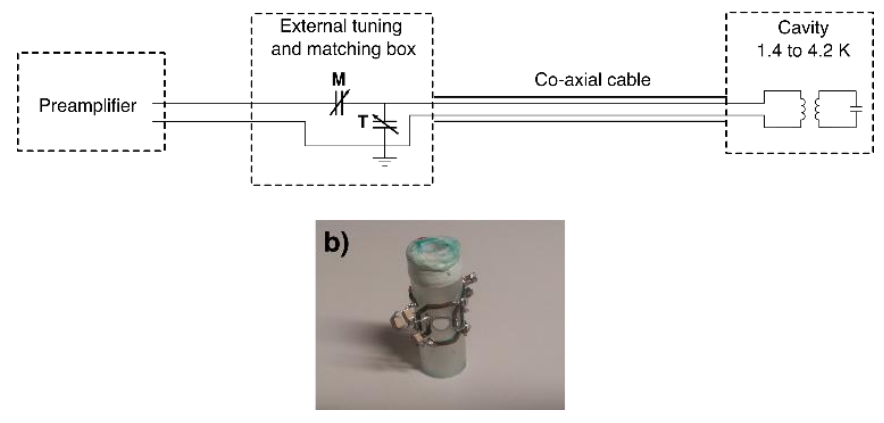

Figure 7: (a) The rf circuit of each channel between the preamplifier and the cavity. The tuning and matching of the $\mathrm{rf}$ coil is refined remotely using variable capacitors ( 8 to $30 \mathrm{pF}$ ) placed in an external box. (b) The double saddle rf coils, which are inductively coupled to two solenoid coils, one for each channel. The copper pieces are glued to a Kel-F support. A hole allows for microwave irradiation.

\section{Sample formulation}

TEMPOL (4-hydroxy-2,2,6,6-tetramethylpiperidin-1-oxyl) was used as polarizing agent. To optimize its concentration for 9.4 T DNP, TEMPOL was dissolved at concentrations between 25 and $100 \mathrm{mM}$ in a mixture of glycerol- $d_{8} / \mathrm{D}_{2} \mathrm{O} / \mathrm{H}_{2} \mathrm{O}$ (v:v:v $\left.=60: 30: 10\right)$ ). For ${ }^{13} \mathrm{C}$ polarization experiments with $1.5 \mathrm{M}$ of $99 \%$ labelled sodium $\left[1-{ }^{13} \mathrm{C}\right]$ acetate, we used TEMPOL with a concentration of $80 \mathrm{mM}$.

Reference polarizations $P\left({ }^{1} \mathrm{H}\right)^{\mathrm{eq}}$ and $P\left({ }^{13} \mathrm{C}\right)^{\mathrm{eq}}$

In order to determine the absolute polarization levels achieved by DNP in the presence of microwave irradiation, the enhanced signals must be compared with reference polarizations, $P\left({ }^{1} \mathrm{H}\right)^{\mathrm{eq}}=0.23 \%$ and $P\left({ }^{13} \mathrm{C}\right)^{\mathrm{eq}}=0.058 \%$ in thermal equilibrium at $9.4 \mathrm{~T}$ and $4.2 \mathrm{~K}$ without DNP (i.e., in the absence of microwave irradiation), which can be calculated from Boltzmann's law if the ratio $B_{0} / T$ is known. The ${ }^{1} \mathrm{H}$ and ${ }^{13} \mathrm{C}$ signal intensities in thermal equilibrium are weak, and tend to be contaminated by background signals that stem from the sample holder and from the probe (traces of frozen water and of organic materials such as glues, etc.) After measuring ${ }^{1} \mathrm{H}$ and ${ }^{13} \mathrm{C}$ signal intensities boosted by DNP, we not only measure ${ }^{1} \mathrm{H}$ and ${ }^{13} \mathrm{C}$ signal intensities of the same sample in the absence of microwave irradiation (green curves on Figure 8), but also of the sample holder after removing the sample, and of the probe after removing the sample holder (respectively, red and green curves in Figure 8 , which are very similar, thus suggesting that most of the background ${ }^{13} \mathrm{C}$ signal comes from the probe). The integrated background signals are then subtracted from the integrated ${ }^{1} \mathrm{H}$ and ${ }^{13} \mathrm{C}$ signal intensities of the sample in the absence of microwave irradiation, and the difference signal thus obtained is used to estimate the solid-state polarization. Clearly, if the thermal background signal is underestimated, the thermal signal that stems from the actual sample will be overestimated, and the absolute polarization levels (and hence the advantage of DNP) will be underestimated. It may be feared that some of the polarization levels reported in the literature suffer from various artifacts, but the solid-state polarizations reported in this paper were carefully estimated using the aforementioned procedure. 


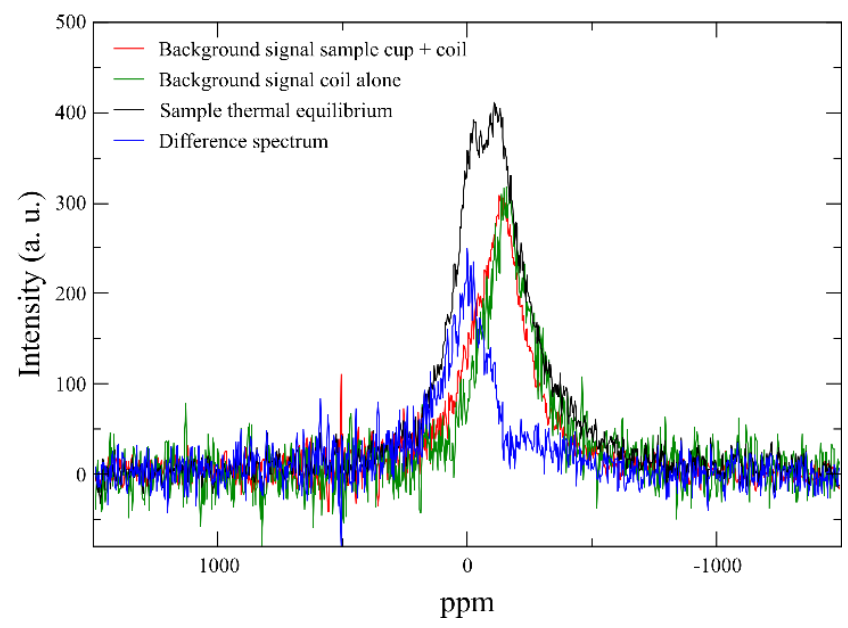

Figure 8: To obtain the correct thermal equilibrium ${ }^{13} \mathrm{C}$ signal at $4.2 \mathrm{~K}$ in the absence of microwave irradiation, one must subtract from the raw signal stemming from the sample, sample holder and probe (black) the background signal from the empty sample cup and probe obtained after the DNP experiments (red or green.) The resulting difference (blue) stems only from the sample and reflects the Boltzmann law. This difference must be compared with the signal obtained with DNP and CP to determine the enhancement of the polarization. A similar behaviour is observed for protons and the same procedure is followed to assess their thermal equilibrium signal.

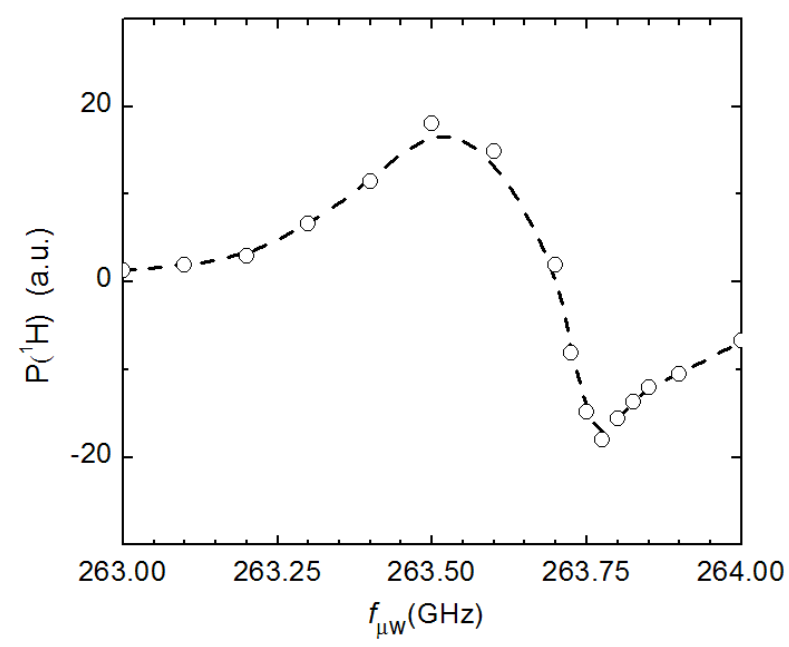

Figure 9: Typical DNP microwave profile: polarization $\mathrm{P}\left({ }^{1} \mathrm{H}\right)$ for a sample containing $50 \mathrm{mM}$ TEMPOL as a function of the monochromatic microwave frequency (i.e., without frequency modulation, $\Delta \mathrm{f}_{\mu \mathrm{w}}=0$ ). The dashed line is represented to guide the eye.

\section{Results}

\section{Optimization of microwave parameters}

The microwave irradiation was optimized to achieve a maximum polarization $P\left({ }^{1} \mathrm{H}\right)$ for a sample containing $50 \mathrm{mM}$ TEMPOL in a mixture of glycerol- $d_{8} / \mathrm{D}_{2} \mathrm{O} / \mathrm{H}_{2} \mathrm{O}$ (v:v:v $\left.=60: 30: 10\right)$ by adjusting the following parameters:

i) The central microwave frequency $f_{\mu w}$;

ii) The range of the frequency modulation $\Delta f_{\mu w}$, at a constant modulation frequency $f_{\text {mod }}=10 \mathrm{kHz}$; iii) The microwave power.

The samples were frozen immediately after preparation to avoid "ripening" effects, which may occur depending on the delay between mixing of the sample and freezing, due to nanophase separations in glycerol/ $/ \mathrm{D}_{2} \mathrm{O}$ mixtures. These effects, which can be either favorable or deleterious for the polarization [17], have not yet been studied at $9.4 \mathrm{~T}$.

In the microwave frequency profile (Figure 9), the positive lobe was found at $263.5 \mathrm{GHz}$, and the negative lobe around $263.75 \mathrm{GHz}$, with a surprisingly small separation of only $250 \mathrm{MHz}$. The separation between the two lobes depends on the concentration of TEMPOL. The range of the frequency modulation $\Delta f_{\mu w}$ seemed to have little effect between 100 and $200 \mathrm{MHz}$ (Figure 10). Finally, even with the maximum available power, the microwave amplitude is not quite sufficient to achieve a complete saturation of the EPR transitions (Figure 11).

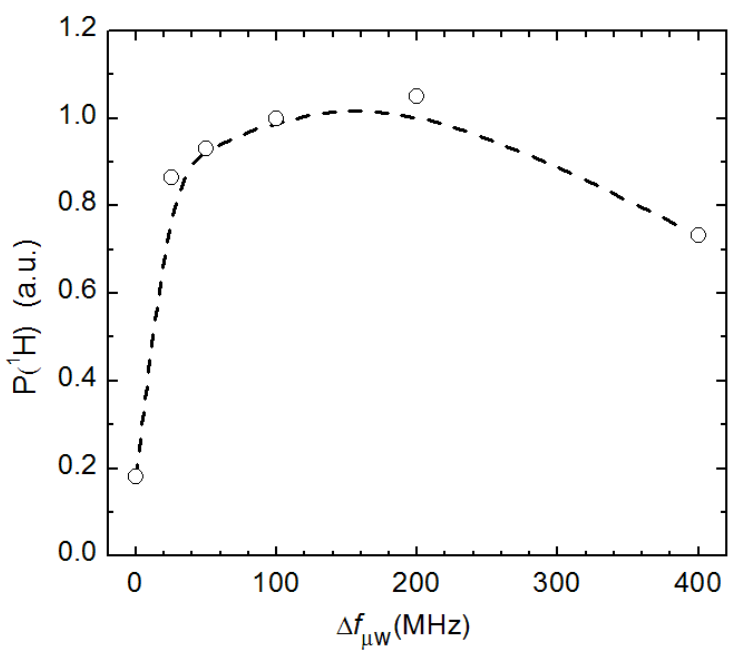

Figure 10: Effect of the modulation range $\Delta \mathrm{f}_{\mu \mathrm{w}}$ on the polarization $\mathrm{P}\left({ }^{1} \mathrm{H}\right)$ for a sample containing $50 \mathrm{mM}$ TEMPOL when the central frequency is set on the positive peak at $263.5 \mathrm{GHz}$ in the microwave profile of Figure 9. The dashed line is represented to guide the eye.

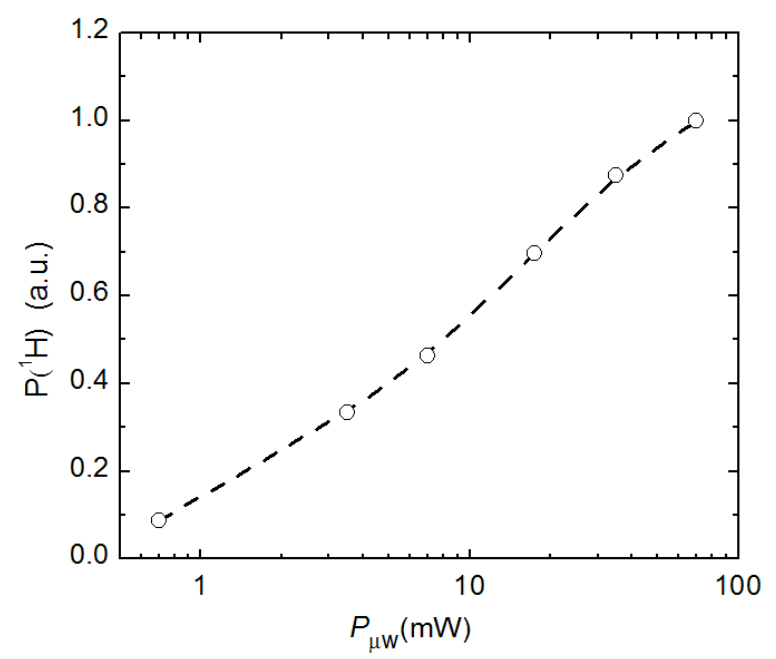

Figure 11: The effect on the proton polarization $\mathrm{P}\left({ }^{1} \mathrm{H}\right)$ of the microwave power for a sample containing $50 \mathrm{mM}$ TEMPOL at $1.5 \mathrm{~K}$. The dashed line is represented to guide the eye. 


\section{Optimization of TEMPOL concentration}

The DNP enhancements were measured for TEMPOL concentrations ranging from 25 to $100 \mathrm{mM}$ (Figure 12). In all cases, the same mixture of glycerol- $d_{8} / \mathrm{D}_{2} \mathrm{O} / \mathrm{H}_{2} \mathrm{O}$ (v:v:v $=60: 30: 10$ ) was used. The optimal TEMPOL concentration is around $80 \mathrm{mM}$, which is higher than the optima found at 6.7 $\mathrm{T}(50 \mathrm{mM})$ and $3.35 \mathrm{~T}(30 \mathrm{mM})$.

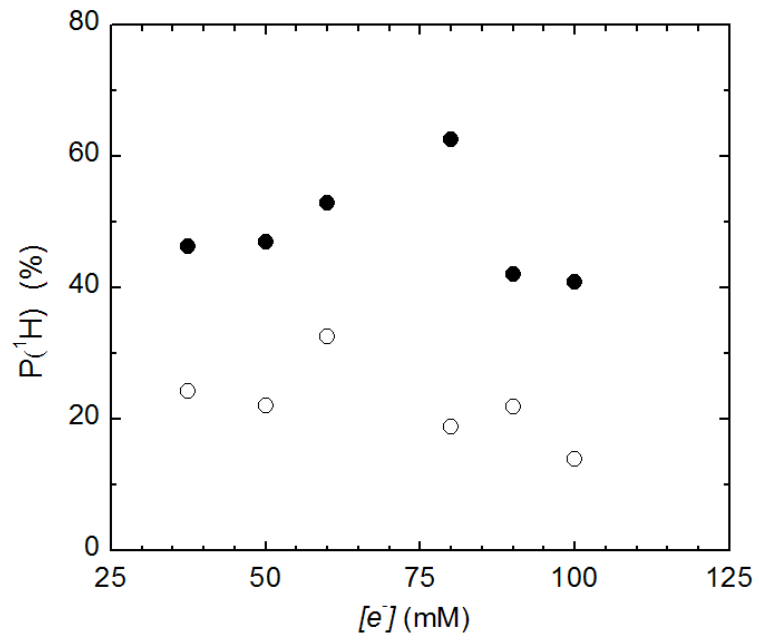

Figure 12: Proton polarizations $\mathrm{P}\left({ }^{1} \mathrm{H}\right)$ at $1.5 \mathrm{~K}$ (filled circles) and $4.2 \mathrm{~K}$ (open circles) as a function of the TEMPOL concentration.

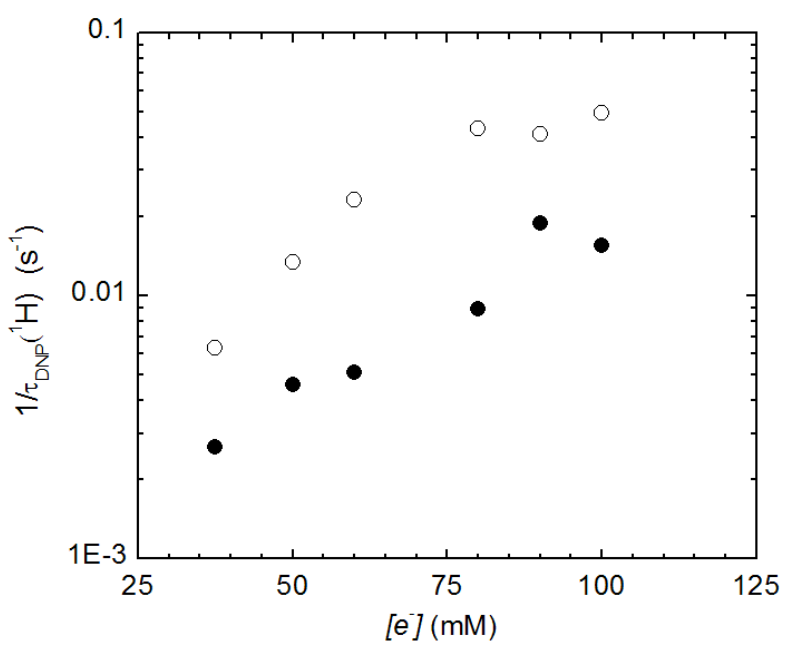

Figure 13: DNP build-up rate $1 / \tau_{\mathrm{DNP}}$ of the proton polarization $\mathrm{P}\left({ }^{1} \mathrm{H}\right)$ as a function of the TEMPOL concentration in glycerol- $\mathrm{d}_{8} / \mathrm{D}_{2} \mathrm{O} / \mathrm{H}_{2} \mathrm{O}(\mathrm{v}: \mathrm{v}: \mathrm{v}=60: 30: 10)$ at $4.2 \mathrm{~K}$ (open circles) and $1.5 \mathrm{~K}$ (filled circles).

The best polarization level $P\left({ }^{1} \mathrm{H}\right)=60 \%( \pm 5 \%)$ was achieved repeatedly with $80 \mathrm{mM}$ TEMPOL. This is lower than $P\left({ }^{1} \mathrm{H}\right)>95 \%$ which was recently achieved for a water sample at $6.7 \mathrm{~T}$ with the so-called HYPSO-5 polarizing agent [18]. On the other hand, the DNP build-up time constant $\tau_{\mathrm{DNP}}\left({ }^{1} \mathrm{H}\right)=120 \mathrm{~s}$ with $80 \mathrm{mM}$ TEMPOL at $9.4 \mathrm{~T}$ is shorter than $\tau_{\mathrm{DNP}}\left({ }^{1} \mathrm{H}\right)=185 \mathrm{~s}$ with $50 \mathrm{mM}$ TEMPOL at $6.7 \mathrm{~T}$ [19]. We believe that this can be attributed to the insufficient or inhomogeneously distributed microwave power at $9.4 \mathrm{~T}$ and the higher temperature $(1.4 \mathrm{~K}$ instead of $1.2 \mathrm{~K}$.
${ }^{1} \mathrm{H}$ to ${ }^{13} \mathrm{C}$ cross polarization $(\mathrm{CP})$

Finally, we compared the slow 'direct' build-up of $P\left({ }^{13} \mathrm{C}\right)$ polarization at $1.4 \mathrm{~K}$ (i.e., in the absence of $\mathrm{CP}$ ) with the accelerated 'indirect' build-up of $P\left({ }^{13} \mathrm{C}\right)$ polarization promoted by repeated Hartmann-Hahn contacts between the thermal baths of the ${ }^{1} \mathrm{H}$ and ${ }^{13} \mathrm{C}$ spins. The sample contained $80 \mathrm{mM}$ TEMPOL, which we had found to be optimal to polarize ${ }^{1} \mathrm{H}$, in a mixture glycerol- $d_{8} / \mathrm{D}_{2} \mathrm{O} / \mathrm{H}_{2} \mathrm{O}(\mathrm{v}: \mathrm{v}: \mathrm{v}=60: 30: 10)$ with $1.5 \mathrm{M}$ isotopically enriched $\left[1-{ }^{13} \mathrm{C}\right]$ acetate. Like at $B_{0}=3.35$ and $6.7 \mathrm{~T}, \mathrm{CP}$ allows one to reach much higher levels of $P\left({ }^{13} \mathrm{C}\right)$ polarization in a significantly shorter time. As shown in Figure 14, a polarization $P\left({ }^{13} \mathrm{C}\right)=50 \pm 5 \%$ was reached in $53 \mathrm{~min}$, after nine $\mathrm{CP}$ steps, performed every $5.3 \mathrm{~min}$ to allow for the polarization $P\left({ }^{1} \mathrm{H}\right)$ to be replenished by DNP in the intervals. Satisfactory polarization levels above $40 \%$ can be reached in about $20 \mathrm{~min}$. In comparison, the direct DNP build-up with TEMPOL merely reaches $P\left({ }^{13} \mathrm{C}\right)=18 \pm 5 \%$ with a time constant $\tau_{\mathrm{DNP}}\left({ }^{13} \mathrm{C}\right)$ of about $1.5 \mathrm{~h}$, although higher levels might be achieved with Trityl and other radicals. The optimum CP conditions were explored systematically (Figure 14): (i) by optimizing the intervals between the $\mathrm{CP}$ contacts, (ii) by optimizing the adiabatic sweeps, (iii) by optimizing the rf amplitudes on both channels, and (iv) by switching the microwaves off $0.5 \mathrm{~s}$ before $\mathrm{CP}$ to allow the electron polarization to return to its equilibrium level after saturation (which significantly extends the proton relaxation time $T_{1 \rho}$ in the rotating frame, and hence makes CP more efficient) [16]. Other sequences with double adiabatic inversions in place of the spin-lock were tested as well. They seem to reach the maximal polarization faster, and display the same level of performance as the microwave-gated CP sequence. Some typical results are shown in Figure 14, with intervals of $2.7 \mathrm{~min}$ and $5.3 \mathrm{~min}$ between the CP steps. The best polarization $P\left({ }^{13} \mathrm{C}\right)=50 \pm 5 \%$ that could be achieved at $9.4 \mathrm{~T}$ is somewhat lower than the record $71 \%$ reached at 6.7 T, using a horizontal solenoidal rf coil that precludes dissolution [19]. Note that certain DNP mechanisms like thermal mixing might be less efficient at higher fields. However, for "routine" operation, a polarization $P\left({ }^{13} \mathrm{C}\right)=50 \%$ is commonly deemed to be sufficient for our applications at 6.7 $\mathrm{T}$, and there is need to achieve a higher polarization at $9.4 \mathrm{~T}$. 

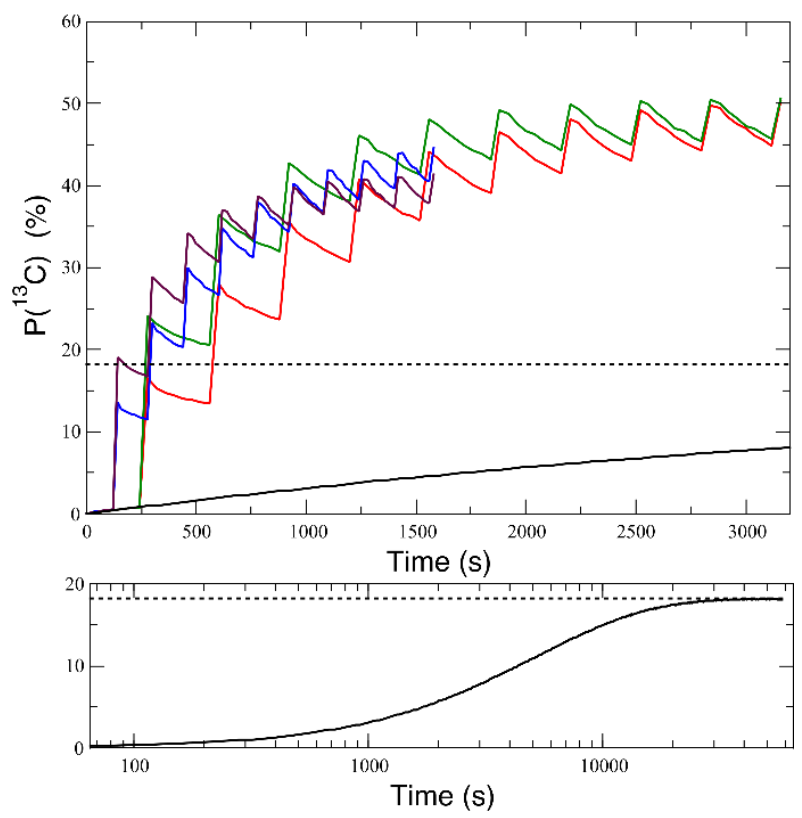

Figure 14: (Red) $\mathrm{CP}$ build up of $P\left({ }^{13} \mathrm{C}\right)$ in a sample of $1.5 \mathrm{M}$ sodium $\left[1-{ }^{13} \mathrm{C}\right]$ acetate and $80 \mathrm{mM}$ TEMPOL in $200 \mathrm{uL}$ of a mixture of glycerol-d8/D2O/H2O (v:v:v $=60: 30: 10$ ) frozen immediately after mixing, with $\mathrm{CP}$ contacts using adiabatic excitation and flip-back pulses of $175 \mu$ s duration on both channels bracketing a $10 \mathrm{~ms}$ spin-lock period, separated by $5.7 \mathrm{~min}$ intervals. (Blue) Same as red curve but with CP contacts separated by 2.7 min intervals. (Brown) Same as blue curve, but with two consecutive simultaneous adiabatic inversions of $11 \mathrm{~ms}$ duration on both channels without spin-lock period. (Green) Same as red curve, but with simultaneous adiabatic inversions. (Black) The beginning of the direct DNP build-up curve of $P\left({ }^{13} \mathrm{C}\right)$ on the same sample. (Below) Complete direct DNP build-up curve of $P\left({ }^{13} \mathrm{C}\right)$ plotted on a logarithmic time-scale. The dashed line indicates the equilibrium value reached by direct DNP after $16 \mathrm{~h}$. All experiments were performed at $1.4 \mathrm{~K}$.

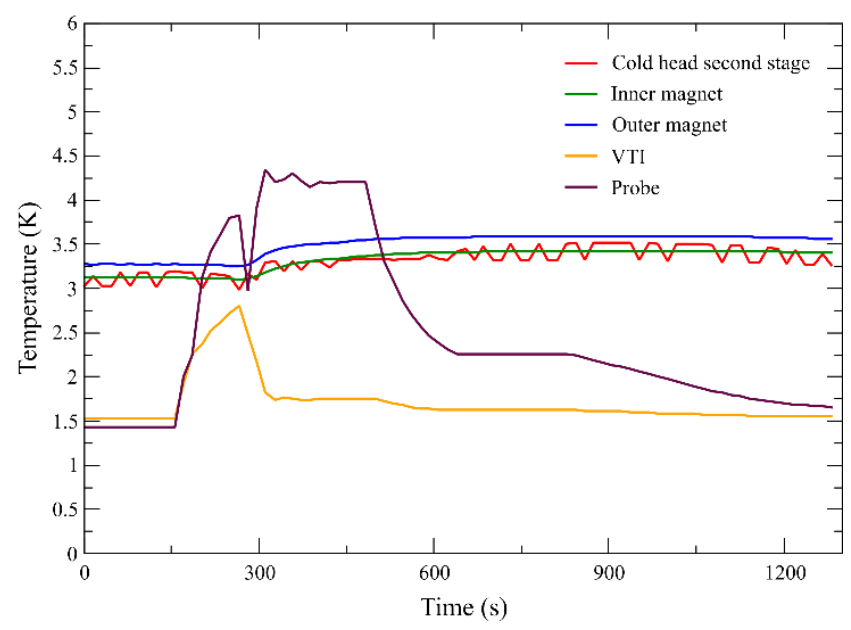

Figure 15: Time-evolution of several key temperature sensors of the apparatus before, during and after dissolution. The dissolution itself occurs around $150 \mathrm{~s}$ on the graph, after the main pump is switched off and the probe heated to $4.2 \mathrm{~K}$ while pressurized gaseous He avoids contamination. The temperature sensors of the magnet indicate a small rise of about $0.3 \mathrm{~K}$, well below the superconducting transition. The dissolution is not performed in the He bath, since the sample is lifted a few centimetres above this bath prior to dissolution.

\section{Dissolution experiments}

By adapting a dissolution unit, originally designed for another polarizer, that can inject ca. $5 \mathrm{~mL}$ of superheated $\mathrm{D}_{2} \mathrm{O}$ at about $1 \mathrm{MPa}$ and $180^{\circ} \mathrm{C}$, the solution was transferred in a few seconds to our $400 \mathrm{MHz}$ and $800 \mathrm{MHz}$ spectrometers (respectively 9.4 and $18.8 \mathrm{~T}$ ) through a magnetic tunnel [20], scavenging the radicals after dissolution [21]. Various temperatures recorded by inner and outer sensors of the magnet, the cold head's second stage as well as the variable temperature insert (VTI) and probe are shown in Figure 15 before, during and after a dissolution. The sample contained $1.5 \mathrm{M}$ sodium $\left[1-{ }^{13} \mathrm{C}\right]$ acetate and $80 \mathrm{mM}$ TEMPOL in $200 \mathrm{uL}$. The enhancement for acetate was about 9800 compared to thermal equilibrium, corresponding to a polarization $P\left({ }^{13} \mathrm{C}\right)=8 \%$ at $400 \mathrm{MHz}$ and $P\left({ }^{13} \mathrm{C}\right)=6.5 \%$ at $800 \mathrm{MHz}$ in solution at room temperature. We are however wary of liquid-state polarization estimates which can strongly vary depending on the method used [22]. These enhancements are similar to routine experiments in our laboratory using a polarizer at $6.7 \mathrm{~T}$.

\section{Conclusions}

We have demonstrated the use of a simple "cryogen-free" $9.4 \mathrm{~T}$ polarizer below $1.5 \mathrm{~K}$ for dissolution-DNP using TEMPOL nitroxide radicals as polarizing agents. While the use of a "cryogen-free" polarizer seems to be a promising strategy for D-DNP, it remains to be seen after further optimization whether increasing the magnetic field from $6.7 \mathrm{~T}$ to $9.4 \mathrm{~T}$ brings significant improvements, for instance regarding the optimum radical concentration required to perform $\mathrm{CP}$ from ${ }^{1} \mathrm{H}$ to ${ }^{13} \mathrm{C}$. Here, a polarization up to $P\left({ }^{1} \mathrm{H}\right)=60 \pm 5 \%$ was obtained with a remarkably short build-up time constant $\tau_{\mathrm{DNP}}\left({ }^{1} \mathrm{H}\right)<120 \mathrm{~s}$. After cross-polarization at $1.5 \mathrm{~K}$, a polarization $P\left({ }^{13} \mathrm{C}\right)=50 \%$ was reached in $53 \mathrm{~min}$, while $P\left({ }^{13} \mathrm{C}\right)>40 \%$ can be obtained within $30 \mathrm{~min}$. $\mathrm{CP}$ from ${ }^{1} \mathrm{H}$ to ${ }^{13} \mathrm{C}$ may be improved by the use of doubly-tuned rf coils. Another path to achieve higher polarizations might be the use of other free radicals, starting with Trityl for direct ${ }^{13} \mathrm{C}$ polarization, but also nitroxide derivatives other than TEMPOL with which we obtained all the results presented in this paper. Another option that we are investigating right now is also the $\mathrm{CP}$ sequence itself, with the implementation of double adiabatic half passage to replace the spin-lock. Preliminary dissolution experiments were performed, showing the robustness of the apparatus that can withstand the process.

\section{Acknowledgements}

The authors would like to thank Thomas Kress and Dr Dennis Kurzbach for their help in developing the dissolution system. We acknowledge support of the European Research Council under the European Union's Horizon 2020 research and innovation program (ERC Grant Agreement $n^{\circ} 714519 /$ HP4all, and ERC Grant Agreement Number 339754/Dilute para-water), the EPFL, the ENS, the CNRS, the Swiss National Science Foundation, and Bruker Biospin.

\section{References}

[1] J. H. Ardenkjaer-Larsen, B. Fridlund, A. Gram, G. Hansson, L. Hansson, M. H. Lerche, R. Servin, M. Thaning, and K. Golman, "Increase in signal-to-noise ratio of $>10,000$ times in liquid-state NMR," Proc. Natl. Acad. Sci., vol. 100, no. 18, pp. 10158-10163, Sep. 2003. 
[2] L. Lumata, Z. Kovacs, A. D. Sherry, C. Malloy, S. Hill, J. van Tol, L. Yu, L. Song, and M. E. Merritt, "Electron spin resonance studies of trityl OX063 at optimal concentration for DNP," Phys. Chem. Chem. Phys. PCCP, vol. 15, no. 24, pp. 9800-9807, Jun. 2013.

[3] A. Comment, B. van den Brandt, K. Uffmann, F. Kurdzesau, S. Jannin, J. a. Konter, P. Hautle, W. T. Wenckebach, R. Gruetter, and J. j. van der Klink, "Design and performance of a DNP prepolarizer coupled to a rodent MRI scanner," Concepts Magn. Reson. Part B Magn. Reson. Eng., vol. 31B, no. 4, pp. 255-269, Oct. 2007.

[4] J. Wolber, F. Ellner, B. Fridlund, A. Gram, H. Jóhannesson, G. Hansson, L. H. Hansson, M. H. Lerche, S. Månsson, R. Servin, M. Thaning, K. Golman, and J. H. Ardenkjaer-Larsen, "Generating highly polarized nuclear spins in solution using dynamic nuclear polarization," Nucl. Instrum. Methods Phys. Res. Sect. Accel. Spectrometers Detect. Assoc. Equip., vol. 526, no. 1, pp. 173-181, Jun. 2004.

[5] J. H. Ardenkjaer-Larsen, A. M. Leach, N. Clarke, J. Urbahn, D. Anderson, and T. W. Skloss, "Dynamic nuclear polarization polarizer for sterile use intent," NMR Biomed., vol. 24, no. 8, pp. 927-932, Oct. 2011.

[6] H. A. I. Yoshihara, E. Can, M. Karlsson, M. H. Lerche, J. Schwitter, and A. Comment, "High-field dissolution dynamic nuclear polarization of [1-13C]pyruvic acid," Phys. Chem. Chem. Phys., vol. 18, no. 18, pp. 12409-12413, May 2016.

[7] A. Kiswandhi, P. Niedbalski, C. Parish, Q. Wang, and L. Lumata, "Assembly and performance of a $6.4 \mathrm{~T}$ cryogen-free dynamic nuclear polarization system," Magn. Reson. Chem., vol. 55, no. 9, pp. 846-852, Sep. 2017.

[8] S. Bowen, O. Rybalko, J. R. Petersen, and J. H. Ardenkjaer-Larsen, "Multi-Field Cryogen Free Dissolution-DNP at 3.35, 6.70, and 10.05 T," presented at the EUROMAR, Warsaw, Poland, 2017.

[9] M. Baudin, B. Vuichoud, A. Bornet, J. Milani, G. Bodenhausen, and S. Jannin, " $>60 \% 1 \mathrm{H}$ Polarization with $\tau \mathrm{DNP}<2$ min using a Cryofree 9.4 T d-DNP Polarizer," presented at the 58th ENC, 2017.

[10] S. Jannin, A. Bornet, S. Colombo, and G. Bodenhausen, "Lowtemperature cross polarization in view of enhancing dissolution Dynamic Nuclear Polarization in NMR," Chem. Phys. Lett., vol. 517, no. 4-6, pp. 234-236, Dec. 2011.

[11] A. Bornet, R. Melzi, S. Jannin, and G. Bodenhausen, “Cross Polarization for Dissolution Dynamic Nuclear Polarization Experiments at Readily Accessible Temperatures 1.2 to $4.2 \mathrm{~K}$," Appl. Magn. Reson., vol. 43, no. 1-2, pp. 107-117, Jul. 2012.

[12] A. Bornet, R. Melzi, Perez Linde, A.-J., P. Hautle, Van Den Brandt, B., S. Jannin, and G. Bodenhausen, "Boosting dissolution dynamic nuclear polarization by cross polarization," J. Phys. Chem. Lett., vol. 4, no. 1, pp. 111-114, 2013.

[13] M. Batel, M. Krajewski, A. Däpp, A. Hunkeler, B. H. Meier, S. Kozerke, and M. Ernst, "Dissolution dynamic nuclear polarization efficiency enhanced by Hartmann-Hahn cross polarization," Chem. Phys. Lett., vol. 554, pp. 72-76, Dec. 2012.

[14] H.-Y. Chen and C. Hilty, "Implementation and Characterization of Flow Injection in Dissolution Dynamic Nuclear Polarization NMR Spectroscopy," ChemPhysChem, vol. 16, no. 12, pp. 2646-2652, Aug. 2015.

[15] A. Bornet, J. Milani, B. Vuichoud, A.-J. Perez Linde, G. Bodenhausen, and S. Jannin, "Microwave frequency modulation to enhance Dissolution Dynamic Nuclear Polarization," Chem. Phys.
Lett., vol. 602, pp. 63-67, May 2014.

[16] A. Bornet, A. Pinon, A. Jhajharia, M. Baudin, X. Ji, L. Emsley, G. Bodenhausen, J. H. Ardenkjaer-Larsen, and S. Jannin, "Microwavegated dynamic nuclear polarization," Phys. Chem. Chem. Phys., vol. 18, no. 44, pp. 30530-30535, Nov. 2016.

[17] E. Weber, G. Sicoli, H. Vezin, G. Frébourg, D. Abergel, G. Bodenhausen, and D. Kurzbach, "Sample Ripening through Nanophase Separation Impacts the Performance of Dynamic Nuclear Polarization," Angew. Chem., vol. 57, pp. 5171-5175, 2018.

[18] M. Cavaillès, A. Bornet, X. Jaurand, B. Vuichoud, D. Baudouin, M. Baudin, L. Veyre, G. Bodenhausen, J.-N. Dumez, S. Jannin, C. Copéret, and C. Thieuleux, "Tailored Microstructured Hyperpolarizing Matrices for Optimal Magnetic Resonance Imaging," Angew. Chem. Int. Ed Engl., vol. 57, pp. 5453-5457, Feb. 2018.

[19] S. Jannin, A. Bornet, R. Melzi, and G. Bodenhausen, "High field dynamic nuclear polarization at $6.7 \mathrm{~T}$ : Carbon-13 polarization above 70\% within 20 min," Chem. Phys. Lett., vol. 549, pp. 99-102, Oct. 2012.

[20] J. Milani, B. Vuichoud, A. Bornet, P. Miéville, R. Mottier, S. Jannin, and G. Bodenhausen, "A magnetic tunnel to shelter hyperpolarized fluids," Rev. Sci. Instrum., vol. 86, no. 2, p. 24101, Feb. 2015

[21] P. Miéville, P. Ahuja, R. Sarkar, S. Jannin, P. R. Vasos, S. Gerber-Lemaire, M. Mishkovsky, A. Comment, R. Gruetter, O. Ouari, P. Tordo, and G. Bodenhausen, "Scavenging Free Radicals To Preserve Enhancement and Extend Relaxation Times in NMR using Dynamic Nuclear Polarization," Angew. Chem. Int. Ed., vol. 49, no. 35, pp. 6182-6185, 2010.

[22] B. Vuichoud, J. Milani, Q. Chappuis, A. Bornet, G. Bodenhausen, and S. Jannin, "Measuring absolute spin polarization in dissolutionDNP by Spin PolarimetrY Magnetic Resonance (SPY-MR)," $J$. Magn. Reson., vol. 260, pp. 127-135, Nov. 2015. 
